\title{
National Estimates Of Emergency Department Visits For Pediatric Severe Sepsis In The United States
}

OBJECTIVE: We sought to determine the characteristics of children presenting to United States (US) Emergency Departments (ED) with severe sepsis.

STUDY DESIGN: Cross-sectional analysis using data from the National Hospital Ambulatory Medical Care Survey (NHAMCS). Using triage vital signs and ED diagnoses (defined by the International Classification of Diseases, Ninth Revision codes), we identified children $<18$ years presenting with both infection (triage fever or ICD-9 infection) and organ dysfunction (triage hypotension or ICD-9 organ dysfunction).

RESULTS: Of 28.2 million pediatric patients presenting to US EDs each year, severe sepsis was present in 95,055 (0.34\%; 95\% CI: 0.29-0.39\%). Fever and respiratory infection were the most common indicators of an infection. Hypotension and respiratory failure were the most common indicators of organ dysfunction. Most severe sepsis occurred in children ages 31 days-1 year old (32.1\%). Most visits for pediatric severe sepsis occurred during winter months (37.4\%), and only

$11.1 \%$ of patients arrived at the ED by ambulance. Over half of severe sepsis cases were self-pay or insured by Medicaid. A large portion (44.1\%) of pediatric severe sepsis ED visits occurred in the South census region. ED length of stay was over 3 hours, and 16.5\% were admitted to the hospital.

CONCLUSION: Nearly 100,000 children annually present to US EDs with severe sepsis. The findings of this study highlight the unique characteristics of children treated in the ED for severe sepsis. 
Pediatric Severe Sepsis

Page 1 of 17

\section{NATIONAL ESTIMATES OF EMERGENCY DEPARTMENT VISITS FOR PEDIATRIC SEVERE SEPSIS IN THE UNITED STATES}

Sara S. Singhal, MD (1)

Mathias W. Allen, MD (1)

John-Ryan McAnnally, MD (1)

Kenneth S. Smith, MD (1)

John P. Donnelly, BS (2)

Henry E. Wang, MD, MS (3)

(1) University of Alabama School of Medicine

(2) Department of Epidemiology, University of Alabama at Birmingham

(3) Department of Emergency Medicine, University of Alabama School of Medicine

The authors have no financial affiliations.

\section{Contact:}

Henry E. Wang, MD, MS

Department of Emergency Medicine

University of Alabama at Birmingham

$61919^{\text {th }}$ St. South, OHB 251

Birmingham, AL 35249

205-996-6526

hwang@uabmc.edu

Running head: Pediatric Severe Sepsis

Word Count: 2,857 
Pediatric Severe Sepsis

Page 2 of 17

\section{INTRODUCTION}

46 Severe sepsis is the syndrome of systemic inflammatory response to microbial infection

47 complicated by organ dysfunction. In adults, severe sepsis poses a major public health burden,

48 resulting in over 750,000 hospitalizations, 500,000 Emergency Department (ED) visits, and over

49 200,000 deaths in the United States (US) annually (Angus et al. 2001; Wang et al. 2007). The

50 estimated cost of adult severe sepsis in the US is over \$16 billion annually (Angus et al. 2001).

51 Severe sepsis is also a prominent condition among children in the US. Watson et al. estimated

52 that there are over 42,000 annual pediatric hospital admissions for severe sepsis in the US, with a

53 mortality rate of 10.2\% (Watson \& Carcillo 2005). Children admitted with severe sepsis had an

54 average length of stay of 31 days at a cost of over $\$ 40,000$, translating to an estimated annual US

55 cost of $\$ 1.7$ billion (Watson et al. 2003).

56 As in adults, early aggressive therapy of severe sepsis is associated with improved outcomes in

57 children (Carcillo et al. 1991; de Oliveira 2010). In children with septic shock, Han et al.

58 observed increases in mortality odds with delays in fluid and inotrope delivery (Han et al. 2003).

59 The ED is an important component of pediatric sepsis care, presenting one of the earliest

60 opportunities for recognition and treatment of the condition. However, the limited information

61 regarding children receiving care for severe sepsis in US EDs presents a major gap in current

62 sepsis knowledge. Data regarding number and types of patients, their characteristics, the

63 therapies provided, and their outcomes could help to characterize the national burden of pediatric

64 severe sepsis to US EDs and could inform strategies to optimize the delivery of pediatric severe

65 sepsis care nationally. 
Pediatric Severe Sepsis

Page 3 of 17

66 In this study we sought to determine the characteristics of ED visits by children for severe sepsis

67 in the US. 
Pediatric Severe Sepsis

Page 4 of 17

\section{METHODS}

69 Study Design

70 Written approval from the University of Alabama at Birmingham Institutional Review Board was

71 obtained for this study. This study was a cross-sectional analysis using the National Hospital

72 Ambulatory Medical Care Survey (NHAMCS).

\section{Data Source}

74 Operated by the National Center for Health Statistics, NHAMCS is a national probability sample

75 characterizing ED visits at hospitals across the US (슨). Standard sampling methods have

76 been utilized by NHAMCS since its inception in 1973. Briefly, the study uses a four-stage

77 probability design, sampling geographically defined areas, hospitals within these areas,

78 emergency service areas within the emergency departments of the hospitals, and patient visits to

79 the emergency services areas. For selected ED facilities, NHAMCS systematically selects

80 records for approximately 100 ED visits in an assigned four-week period. The National Center

81 for Health Statistics (NCHS) works with each hospital to abstract clinical data from selected

82 charts. Each observation in NHAMCS reflects an individual ED visit; the data do not identify

83 individual persons. The NHAMCS data collected in this manner have been used in over 500

84 publications (McCaig \& Burt 2012). For this study, we used NHAMCS public-use data for the

85 nine-year period 2001-2009. 
Pediatric Severe Sepsis

Page 5 of 17

86

87 The primary outcome was severe sepsis, defined as presentation to the ED with both 1) infection and 2) evidence of organ dysfunction (Goldstein et al. 2005). This approach has been widely used in a range of studies characterizing sepsis epidemiology (Angus et al. 2001; Wang et al. 2007; Weycker et al. 2003). We used a combination of triage vital signs and ED diagnoses as 9 indicators of an infection and/or organ dysfunction. For each ED visit, NHAMCS reported up to 92 We did not use blood culture results to define sepsis.

94 As described in prior studies, we identified infections using a taxonomy of ICD-9 codes 95 96 97 were not available. NHAMCS did not report the route of temperature measurement.

101 To identify organ dysfunction, we similarly followed the ICD-9 taxonomy of Angus, et al. but

102 added additional criteria (Angus et al. 2001). Additional ICD-9 codes representing organ

103 dysfunction included 518.8 (respiratory failure), 786.03 (apnea), 799.1 (respiratory arrest),

104990.90 (systemic inflammatory response syndrome/SIRS-not otherwise specified) and 995.92

105 (SIRS-infection with organ dysfunction) (Angus et al. 2001; Wang et al. 2007). We added ED 106 endotracheal intubation as a form of organ dysfunction (respiratory failure). We also included ED 
Pediatric Severe Sepsis

Page 6 of 17

107 triage hypotension an indicator of organ dysfunction (circulatory system failure), using

108 international age-specific definitions for hypotension (Gebara 2005; Goldstein et al. 2005).

109 (Appendix) We opted not to use organ dysfunction definitions proposed by Goldstein, et al.

110 because of the unavailability laboratory test values and physiologic measures in the NHAMCS

111 data set (Goldstein et al. 2005).

\section{Covariates}

113 Demographic characteristics included age, sex, race, ethnicity, hospital geographic region and

114 population setting, month of visit and mode and time of arrival. Sex, race and ethnicity

115 information was missing for some of the study population ( $0.86 \%$ missing sex information,

116 12.4\% missing race and 17.5\% missing ethnicity). Therefore, these characteristics were assessed

117 using imputed variables provided by NHAMCS (대) $)$ Geographic regions were based upon

118 US Census Regions (Northeast, Midwest, West and South). Population setting consisted of

119 hospitals in Metropolitan Statistical Areas (MSA) and non-MSAs. Month of visit was

120 categorized as fall (September/October/November), winter (December/January/February), spring

121 (March/April/May) or summer (June/July/August). Mode of arrival was categorized as arrival by

122 ambulance vs. other. We divided time of arrival into 8-hour intervals: 7 am-3 pm, 3 pm-11 pm,

123 and 11 pm-7 am. We also examined length of ED stay, admission to the hospital, admission

124 destination and hospital discharge status. Initial ED vital signs were also examined, including

125 heart rate (beats/min), systolic blood pressure (mm Hg), and temperature (degrees Fahrenheit). 
Pediatric Severe Sepsis

Page 7 of 17

\section{Data Analysis}

127 Using descriptive statistics, we determined the annual number and characteristics of pediatric

128 severe sepsis cases. We divided the patient cohort into five age subgroups to reflect definitions

129 for neonates (0-30 days), infants (31 days-1 year), toddler and preschool (2-5 years), school age

130 children (6-12 years), and adolescents (13-18 years) (Goldstein et al. 2005). We incorporated

131 sampling design and weight variables to calculate nationally weighted estimates and their

132 corresponding 95\% confidence intervals. Performing the analysis in this manner allowed for

133 valid estimation of all statistics and variances, accounting for the complex survey design.

134 The NCHS considers estimates based upon fewer than 30 raw observations (or those with greater

135 than 30\% relative standard error) to be unreliable. Therefore, we collapsed subcategories to

136 ensure that table cells contained a sufficient number of raw observations. For example, we

137 combined hematological, neurologic, hepatic and other organ dysfunctions into a single category.

138 We used ultimate cluster design (single stage sampling) in variance and 95\% confidence interval

139 calculations, utilizing "masked" stratum and primary sampling unit identifiers provided with the

140 NHAMCS public-use data set (ㄷS). Prior efforts have demonstrated that variance estimates

141 using these methods are conservative (Hing et al. 2003). We conducted all analyses using Stata

142 v.12 (Stata, College Station, TX). 
Pediatric Severe Sepsis

Page 8 of 17

\section{RESULTS}

144 An estimated 1.05 billion ED visits occurred in the U.S. during the nine-year study period

145 (2001-2009), of which 253.4 million (24.1\%) involved children <18 years of age, translating to

146 approximately 28.2 million pediatric emergency visits annually. (Table 1) One in three (34.3\%)

147 pediatric ED visits involved children with signs of infection, and approximately 1\% involved

148 organ dysfunction. The presence of a fever and an ED diagnosis for respiratory infection were

149 the most common indicators of infection. (Table 2) Hypotension and respiratory failure were the

150 most common indicators of organ dysfunction.

151 Severe sepsis was present in 95,055 cases annually, representing 0.34\% (95\% CI: 0.29-0.39\%) of

152 all pediatric ED visits. The annual number of pediatric ED visits for severe sepsis declined

153 slightly during 2001-2009. (Figure 1)

154 Children between ages 31 days-1 year comprised the largest proportion of severe sepsis cases.

155 Most patients were white and non-Hispanic. Most pediatric severe sepsis ED visits occurred

156 during winter months (37.4\%). Almost half (45\%) of pediatric severe sepsis patients arrived

157 between 3:00 PM and 10:59 PM. Only 11.1\% arrived by ambulance. Most pediatric severe sepsis

158 visits occurred at hospitals in Metropolitan Service Areas. While most severe sepsis ED visits

159 occurred in the South census region (40\%), the proportions of severe sepsis in each region were

160 similar $(\mathrm{p}=0.40)$. Over half of pediatric severe sepsis cases were self-pay or insured by Medicaid.

161 Pediatric severe sepsis patients spent over three hours in the ED. In the NHAMCS data set, 
Pediatric Severe Sepsis

Page 9 of 17

$16216.5 \%$ of pediatric severe sepsis ED visits resulted in hospital admission, and 3.1\% were

163 admitted to a critical care unit. 
Pediatric Severe Sepsis

Page 10 of 17

\section{DISCUSSION}

165 Our study suggests that there are almost 100,000 ED visits for pediatric severe sepsis each year

166 in the US. Severe sepsis is associated with significant morbidity and mortality, and early

167 aggressive therapy may help to improve outcomes from this condition (Rivers et al. 2001). Our

168 study illustrates the potential magnitude of ED pediatric severe sepsis population in the United

169 States. While there are limitations inherent to the NHAMCS data set, our observations offer the

170 best available and most current cross-sectional perspectives of pediatric severe sepsis in the US.

171 Our findings shed light on the characteristics of children requiring severe sepsis care in the ED.

172 The age distribution of severe sepsis was bimodal, with most cases occurring in children ages 31

173 days-1 year and 13-18 years. Only 11.1\% arrived by EMS, indicating opportunities to expand the

174 involvement of EMS in the care and transportation of these children (Wang et al. 2010). The

175 insurance payor for over half of severe sepsis cases was Medicaid or self-pay, highlighting the

176 prevalence of this condition among those with lower socioeconomic status. While not indicated

177 by these data, barriers to timely primary or preventive care may have amplified the number of

178 ED visits by this subgroup.

179 Using 1995 hospital discharge data from seven states, Watson, et al. estimated that there were

180 42,364 annual hospitalizations for pediatric severe sepsis in the US (Watson \& Carcillo 2005).

181 Our contrasting study focuses on children presenting to the ED, which is often the location for

182 initial detection and management of sepsis. In contrast to the Watson study, we observed only

183 16,000 annual pediatric severe sepsis hospital admissions from the ED as well as low rates of 


\section{Pediatric Severe Sepsis}

\section{Page 11 of 17}

184 critical care unit admission. We urge caution when making inferences from these unexpected

185 observations, which are clearly discordant with Watson's prior work. There are many potential

186 explanations for the disagreement between Watson's and our study. Watson's study included low

187 birth weight neonates in neonatal intensive care units, which is not representative of the general

188 ED population. The majority of cases in the Watson series may reflect children who developed

189 severe sepsis during later points of hospitalization. Many pediatric patients in our series may

190 have received successful initial treatment with sufficient recovery for discharge home from the

191 ED. The data from the Watson study are also almost 18 years old, and may not represent current 192 patient characteristics or clinical practices.

193 However, another potential explanation is that NHAMCS coding or data abstraction errors

194 unique to the data set or this population may have resulted in underestimates of the number of

195 admissions. Recent studies highlight concerns with NHAMCS data pertaining to hospital

196 admission status or destination; these factors clearly apply to our analysis (Cooper 2012; Green

197 2012; McCaig \& Burt 2012). We note that we did not perform an independent validation of the

198 NHAMCS dataset for this particular analysis. However, a proper validation study would be

199 logistically challenging, requiring manual review of medical records from multiple ED’s. We

200 emphasize that these inconsistencies related to ED disposition should not distract from the main

201 premise of our study - that the annual number of US ED visits for severe sepsis is large and

202 diverse. Our study is intended to be hypothesis generating and to provide foundation knowledge

203 for characterizing the collective burden of pediatric severe sepsis upon the US emergency care 204 system. 


\section{Pediatric Severe Sepsis}

\section{Page 12 of 17}

205 The findings of our study highlight important issues in pediatric sepsis care. The care of the

206 pediatric severe sepsis patient is often complex, involving early recognition and aggressive

207 resuscitative care. Outcomes for complex medical conditions are often better at centers that care

208 for high volumes of patients; for example, trauma centers that care for larger volumes of injured

209 patients report improved survival (Nathens et al. 2001). The National Emergency Department

210 Inventory (NEDI-USA) estimated that there were 4,874 EDs in the US in 2007 (NEDI-USA).

211 Based upon this figure and our finding of approximately 100,000 annual ED visits for pediatric

212 severe sepsis, one would expect a typical ED to care for approximately 20 pediatric severe sepsis

213 cases each year. If additional studies were to confirm a minimum experience threshold, clinicians

214 and policymakers might entertain alternate pediatric sepsis care strategies. For example,

215 providers might triage pediatric severe sepsis cases to specialized pediatric EDs with expertise in

216 sepsis resuscitation. Clinicians may also devise ways to improve severe sepsis recognition, such

217 as through the use of point-of-care lactate measurements (Levy et al. 2010; $\underline{\text { Perel 2008; }} \underline{\text { Rivers et }}$

218 al. 2001). We emphasize that our study does not indicate the effectiveness of such approaches.

219 Rather, our study highlights the sizable pediatric population that could benefit from optimized

220 severe sepsis detection and management. 
Pediatric Severe Sepsis

Page 13 of 17

221 LIMITATIONS

222 NHAMCS is retrospective in nature and uses a probability sample design. However, the

223 methodology of the NHAMCS study is rigorous, and the data set has been widely used in similar

224 analyses for over 15 years. Due to the absence of individual identifiers, we could not estimate

225 rates of ED re-visits. Because NHAMCS collects only three diagnoses per patient, we may have

226 missed additional relevant conditions that were not reported by data abstractors. Abstractors may

227 have also varied in the selection of ED diagnoses; it is unclear whether this bias would have

228 resulted in under- or over-estimates of the number of severe sepsis cases. Our focus on children

229 resulted in a relatively modest sample size, limiting inferences for smaller subgroups. Most

230 notably, while representing an important sepsis subset, our ability to characterize neonates was

231 limited. We note that given the current data we could not correct ages for those born prematurely.

232 As discussed previously, the identification of severe sepsis using diagnostic codes and vital signs

233 has not been prospectively validated with the current data set, an effort that would be logistically

234 complex. However, the strategy has been widely used by other studies, including those using

235 NHAMCS (Wang et al. 2007). While Martin, et al. proposed a set of ICD-9 codes corresponding

236 to sepsis, we focused on severe sepsis (encompassing the combination of infection and organ

237 dysfunction codes) in this study because of the unclear coding practices for children (Martin et

238 al. 2003). We note that the definition of sepsis is controversial, and the standards used in this

239 study reflect common practice used in a range of prior studies (Angus et al. 2001; Wang et al.

240 2007). 
Pediatric Severe Sepsis

Page 14 of 17

241 Our analysis was based upon initial vital signs and did not preclude those receiving prior

242 treatment (for example, administrative of antipyretics prior to ED arrival) or those

243 decompensating at later time points in the ED. We were unable to disentangle infectious from

244 non-infectious causes for fever or hypotension in the current data set. We also focused on

245 children presenting to the ED with severe sepsis, not children developing sepsis as a result of

246 hospitalization for other medical conditions. We could not identify conditions such as

247 malignancies or congenital deficiencies that often predispose children to sepsis (Orange 2005).

248 Because of the small relative number of raw observations, we could not provide detailed insights

249 on ED interventions or hospital outcome. Our ability to describe secular trends in sepsis was also

250 limited. 
Pediatric Severe Sepsis

Page 15 of 17

\section{CONCLUSION}

252 Nearly 100,000 children annually present to US EDs with severe sepsis. The findings of this 253 study highlight the unique characteristics of children treated in the ED for severe sepsis. 
Pediatric Severe Sepsis

Page 16 of 17

254 REFERENCES

255

256

257

258

259

260

261

262

263

264

265

266

267

268

269

270

271

272

273

274

275

276

277

278

279

280

281

282

283

Angus DC, Linde-Zwirble WT, Lidicker J, Clermont G, Carcillo J, and Pinsky MR. 2001.

Epidemiology of severe sepsis in the United States: analysis of incidence, outcome, and associated costs of care. Crit Care Med 29:1303-1310.

Carcillo JA, Davis AL, and Zaritsky A. 1991. Role of early fluid resuscitation in pediatric septic shock. JAMA 266:1242-1245.

Cooper RJ. 2012. NHAMCS: Does It Hold Up to Scrutiny? Ann Emerg Med 60:722-725.

de Oliveira CF. 2010. Early goal-directed therapy in treatment of pediatric septic shock. Shock 34 Suppl 1:44-47.

Gebara BM. 2005. Values for systolic blood pressure. Pediatr Crit Care Med 6:500; author reply 500-501.

Goldstein B, Giroir B, and Randolph A. 2005. International pediatric sepsis consensus conference: definitions for sepsis and organ dysfunction in pediatrics. Pediatr Crit Care Med 6:2-8.

Green SM. 2012. Congruence of Disposition After Emergency Department Intubation in the National Hospital Ambulatory Medical Care Survey. Ann Emerg Med.

Han YY, Carcillo JA, Dragotta MA, Bills DM, Watson RS, Westerman ME, and Orr RA. 2003.

Early reversal of pediatric-neonatal septic shock by community physicians is associated with improved outcome. Pediatrics 112:793-799.

Hing E, Gousen S, Shimizu I, and Burt C. 2003. Guide to using masked design variables to estimate standard errors in public use files of the National Ambulatory Medical Care Survey and the National Hospital Ambulatory Medical Care Survey. Inquiry 40:401-415.

Levy B, Perez P, Gibot S, and Gerard A. 2010. Increased muscle-to-serum lactate gradient predicts progression towards septic shock in septic patients. Intensive Care Med 36:1703-1709.

Martin GS, Mannino DM, Eaton S, and Moss M. 2003. The epidemiology of sepsis in the United States from 1979 through 2000. N Engl J Med 348:1546-1554.

McCaig LF, and Burt CW. 2012. Understanding and interpreting the national hospital ambulatory medical care survey: key questions and answers. Ann Emerg Med 60:716-721 e711. 
Pediatric Severe Sepsis

Page 17 of 17

284

285

286

287

288

289

290

291

292

293

294

295

296

297

298

299

300

301

302

303

304

305

306

307

308

309

310

311

312

313

314

315

Nathens AB, Jurkovich GJ, Maier RV, Grossman DC, MacKenzie EJ, Moore M, and Rivara FP. 2001. Relationship between trauma center volume and outcomes. JAMA 285:1164-1171.

NCHS. National Center for Health Statistics, Centers for Disease Control and Prevention, NHAMCS estimation procedures. (Accessed May 31, 2012, at http://www.cdc.gov/nchs/ahcd/ahcd estimation procedures.htm\#nhamcs procedures.).

NCHS. National Center for Health Statistics, Centers for Disease Control and Prevention. Dataset documentation: National Hospital Ambulatory Medical Care Survey. (Accessed May 31, 2012 at ftp://ftp.cdc.gov/pub/Health Statistics/NCHS/Dataset Documentation/NHAMCS/).

NEDI-USA. National Emergency Department Inventories (NEDI) database, EMNet. Emergency Medicine Network. Massachusetts General Hospital. Boston, MA. (Accessed June 8, 2011 at http://www.emnet-usa.org/nedi/nedi usa.htm).

Orange JS. 2005. Congenital immunodeficiencies and sepsis. Pediatr Crit Care Med 6:S99-S107.

Perel A. 2008. Bench-to-bedside review: the initial hemodynamic resuscitation of the septic patient according to Surviving Sepsis Campaign guidelines--does one size fit all? Crit Care 12:223.

Rivers E, Nguyen B, Havstad S, Ressler J, Muzzin A, Knoblich B, Peterson E, and Tomlanovich M. 2001. Early goal-directed therapy in the treatment of severe sepsis and septic shock. $N$ Engl J Med 345:1368-1377.

Wang HE, Shapiro NI, Angus DC, and Yealy DM. 2007. National estimates of severe sepsis in United States emergency departments. Crit Care Med 35:1928-1936.

Wang HE, Weaver MD, Shapiro NI, and Yealy DM. 2010. Opportunities for Emergency Medical Services care of sepsis. Resuscitation 81:193-197.

Watson RS, and Carcillo JA. 2005. Scope and epidemiology of pediatric sepsis. Pediatr Crit Care Med 6:S3-5.

Watson RS, Carcillo JA, Linde-Zwirble WT, Clermont G, Lidicker J, and Angus DC. 2003. The epidemiology of severe sepsis in children in the United States. Am J Respir Crit Care Med 167:695-701.

Weycker D, Akhras KS, Edelsberg J, Angus DC, and Oster G. 2003. Long-term mortality and medical care charges in patients with severe sepsis. Crit Care Med 31:2316-2323. 


\section{Table $\mathbf{1}_{\text {(on next page) }}$}

Emergency department (ED) visits by pediatric patients for severe sepsis 


\section{TABLE 1}

Emergency department (ED) visits by pediatric patients for severe sepsis. CI= Confidence Interval; NA= Not applicable. "Infection" was defined as the presence of fever or hypothermia ( $\mathrm{T}<96.8$ or $>100.4 \mathrm{~F}$ ), or an ICD-9 diagnosis code for infection. "Organ Dysfunction” was defined as the presence of hypotension (based upon age-appropriate ED systolic blood pressure), provision of endotracheal intubation, or an ICD-9 diagnosis code for organ dysfunction.

\begin{tabular}{|c|c|c|c|c|}
\hline Variable & $\begin{array}{l}\text { No. of Raw } \\
\text { Observations }\end{array}$ & $\begin{array}{c}\text { Total } \\
\text { ED Visits } \\
\text { 2001-2009 } \\
\text { (Estimated } \\
\text { 1000s) }\end{array}$ & $\begin{array}{c}\text { Annual } \\
\text { ED Visits } \\
\text { (Estimated } \\
\text { 1000s) }\end{array}$ & $\begin{array}{c}\text { Percentage of } \\
\text { Pediatric } \\
\text { ED Visits } \\
(95 \% \text { CI) }\end{array}$ \\
\hline Total ED Visits & 322,745 & $1,052,914$ & 116,990 & NA \\
\hline $\begin{array}{l}\text { Pediatric (age }<18 \text { years) ED Visits } \\
\text { 2001-2009 }\end{array}$ & 76,444 & 253,417 & 28,157 & NA \\
\hline ED Visits with “Infection” & 26,059 & 86,906 & 9,656 & $34.3(33.5-35.1)$ \\
\hline ED Visits with “Organ Dysfunction” & 794 & 2,640 & 293 & $1.04(0.94-1.15)$ \\
\hline $\begin{array}{l}\text { ED Visits with Severe Sepsis } \\
\text { ("Infection” + “Organ Dysfunction”) }\end{array}$ & 266 & 855 & 95 & $0.34(0.29-0.39)$ \\
\hline
\end{tabular}




\section{Table $2_{\text {(on next page) }}$}

Underlying infections and organ dysfunctions of Emergency Department visits by pediatric patients with suspected severe sepsis (age $<18$ yrs) 


\section{TABLE 2}

Underlying infections and organ dysfunctions of Emergency Department visits by pediatric patients with suspected severe sepsis (age <18 yrs). "Infection" was defined as the presence of fever or hypothermia ( $\mathrm{T}<96.8$ or $>100.4 \mathrm{~F}$ ), or an ICD-9 diagnosis code for infection. "Organ Dysfunction" was defined as the presence of hypotension (based upon age-appropriate ED systolic blood pressure), provision of endotracheal intubation, or an ICD-9 diagnosis code for organ dysfunction.

$\mathrm{CI}=$ confidence interval; SBP=systolic blood pressure. *Estimate based upon $<30$ raw observations, considered unreliable by the National Center for Health Statistics.

\begin{tabular}{|c|c|c|c|c|}
\hline Variable & $\begin{array}{l}\text { Number of } \\
\text { Raw } \\
\text { Observations }\end{array}$ & $\begin{array}{l}\text { Total Number } \\
\text { Of ED } \\
\text { Severe Sepsis } \\
\text { 2001-2009 } \\
\text { (Estimated } \\
\text { 1000s) }\end{array}$ & $\begin{array}{l}\text { Annual } \\
\text { Number } \\
\text { Of ED } \\
\text { Severe Sepsis } \\
\text { (Estimated } \\
\text { 1000s) }\end{array}$ & $\begin{array}{l}\text { Percentage of } \\
\text { ED } \\
\text { Severe Sepsis } \\
(95 \% \text { CI })\end{array}$ \\
\hline & & $\mathbf{N}=855,493$ & $\mathrm{~N}=95,055$ & \\
\hline \multicolumn{5}{|l|}{ “Infection" } \\
\hline Fever ( $<96.8$ or $\geq 100.4$ F) on ED triage & 154 & 489 & 54 & $\begin{array}{c}58.4 \\
(50.6-65.8)\end{array}$ \\
\hline $\begin{array}{l}\text { ED ICD-9 defined infection of respiratory } \\
\text { system }\end{array}$ & 109 & 356 & 40 & $\begin{array}{c}41.6 \\
(33.5-50.2)\end{array}$ \\
\hline $\begin{array}{l}\text { ED ICD-9 defined infection of genitourinary, } \\
\text { digestive, nervous, musculoskeletal, } \\
\text { or circulatory systems or other } \\
\text { infections (parasitic, skin, or } \\
\text { associated with pregnancy) }\end{array}$ & 50 & 183 & 20 & $\begin{array}{c}21.4 \\
(15.4-28.8)\end{array}$ \\
\hline \multicolumn{5}{|l|}{ “Organ Dysfunction” } \\
\hline Hypotension on ED triage & 201 & 632 & 70 & $\begin{array}{c}73.8 \\
(65.9-80.5)\end{array}$ \\
\hline ED ICD-9 defined respiratory dysfunction & 55 & 187 & 21 & $\begin{array}{c}21.9 \\
(15.8-29.4)\end{array}$ \\
\hline $\begin{array}{l}\text { ED cardiovascular, hematological, } \\
\text { neurologic, hepatic, or other organ } \\
\text { dysfunction }\end{array}$ & $16^{*}$ & $56 *$ & $6^{*}$ & $6.6(3.2-13.1)^{*}$ \\
\hline
\end{tabular}




\section{Table 3 (on next page)}

Characteristics of Emergency Department pediatric patients presenting with severe sepsis 


\section{TABLE 3}

Characteristics of Emergency Department pediatric patients presenting with severe sepsis. †Data available for 2003-2009 only. ED=emergency department, CI=confidence interval. *Estimate based on <30 raw observations, considered unreliable by the National Center for Health Statistics.

\begin{tabular}{|c|c|c|c|c|}
\hline Variable & $\begin{array}{c}\text { Number } \\
\text { of Raw } \\
\text { Observations }\end{array}$ & $\begin{array}{l}\text { Total Number } \\
\text { Of ED } \\
\text { Severe Sepsis } \\
\text { (2001-2009) } \\
\text { (Estimated } \\
\text { 1000s) }\end{array}$ & $\begin{array}{l}\text { Annual } \\
\text { Number } \\
\text { Of ED } \\
\text { Severe Sepsis } \\
\text { (Estimated } \\
\text { 1000s) }\end{array}$ & $\begin{array}{c}\text { Percentage of } \\
\text { ED Severe Sepsis } \\
(95 \% \text { CI })\end{array}$ \\
\hline & & $\mathbf{N}=855,493$ & $N=95,055$ & \\
\hline \multicolumn{5}{|l|}{ Age } \\
\hline 0-30 Days & $16^{*}$ & $63 *$ & $7 *$ & $7.3(4.1-12.7)^{*}$ \\
\hline 31 Days-1 Year & 79 & 274 & 30 & $32.1(25.0-40.0)$ \\
\hline 2-5 Years & 46 & 133 & 15 & $15.5(10.8-21.7)$ \\
\hline 6-12 Years & 65 & 180 & 20 & $21.0(16.3-26.6)$ \\
\hline 13-18 Years & 60 & 207 & 23 & $24.2(18.3-31.3)$ \\
\hline \multicolumn{5}{|l|}{ Sex } \\
\hline Male & 120 & 374 & 42 & $43.7(36.2-51.5)$ \\
\hline Female & 146 & 481 & 53 & $56.3(48.5-63.8)$ \\
\hline \multicolumn{5}{|l|}{ Race } \\
\hline White & 189 & 576 & 64 & $67.3(59.3-74.5)$ \\
\hline Black & 61 & 231 & 26 & $27.0(20.5-34.6)$ \\
\hline Other & $16^{*}$ & $49 *$ & $5 *$ & $5.7(3.0-10.8)^{*}$ \\
\hline \multicolumn{5}{|l|}{ Ethnicity† } \\
\hline Hispanic & 52 & 155 & 17 & $23.8(17.1-32.2)$ \\
\hline Not Hispanic & 148 & 494 & 55 & $76.2(67.8-82.9)$ \\
\hline \multicolumn{5}{|l|}{ Season } \\
\hline Fall (Sept, Oct, Nov) & 65 & 204 & 23 & $23.9(17.9-31.1)$ \\
\hline Winter (Dec, Jan, Feb) & 91 & 320 & 36 & $37.4(29.6-46.0)$ \\
\hline Spring (Mar, Apr, May) & 61 & 199 & 22 & $23.2(16.7-31.3)$ \\
\hline Summer (Jun, Jul, Aug) & 49 & 133 & 15 & $15.5(10.5-22.4)$ \\
\hline \multicolumn{5}{|l|}{ Arrival Time } \\
\hline 7:00AM - 2:59PM & 100 & 312 & 35 & $36.5(29.2-44.5)$ \\
\hline 3:00PM - 10:59PM & 116 & 390 & 43 & $45.7(38.6-53.0)$ \\
\hline 11:00PM - 6:59AM & 49 & 152 & 17 & $17.8(12.4-24.8)$ \\
\hline \multicolumn{5}{|l|}{ Arrival By Ambulance† } \\
\hline Yes & $22 *$ & $66^{*}$ & $7 *$ & $11.1(6.6-18.0)^{*}$ \\
\hline No & 164 & 529 & 59 & $88.9(82.0-93.4)$ \\
\hline
\end{tabular}


Region

Northeast 62

Midwest $\quad 50$

142

16

$16.6(12.0-22.5)$

South

96

162

18

$18.9(13.2-26.4)$

West

377

$44.1(35.7-52.9)$

58

174

$20.3(14.1-28.4)$

Hospital Population Setting

Metropolitan Statistical Area

223

651

72

76.1 (64.6-84.7)

(MSA)

Non-MSA

205

23

$23.9(15.3-35.4)$

Payor Type

Private Insurance

274

30

$32.2(25.9-39.2)$

Medicaid

443

$45 *$

Self-Pay

133

49

$51.9(44.0-59.8)$

$17 *$

5*

$5.3(3.1-9.0)^{*}$

Other

$90 *$

$10 *$

$10.6(6.3-17.3)^{*}$

Admitted to Hospital

Yes

50

141

16

$16.5(11.3-23.5)$

No

216

715

79

83.5 (76.5-88.8)

Admitted to Critical Care Unit

Yes

$13 *$

$27 *$

3*

$3.1(1.4-6.8)^{*}$

No

253

829

92

$96.9(93.2-98.6)$

$3.3(2.6-4.0)$ 


\section{Figure 1}

Number of pediatric severe sepsis Emergency Department visits by three-year interval, United States, 2001-2009.

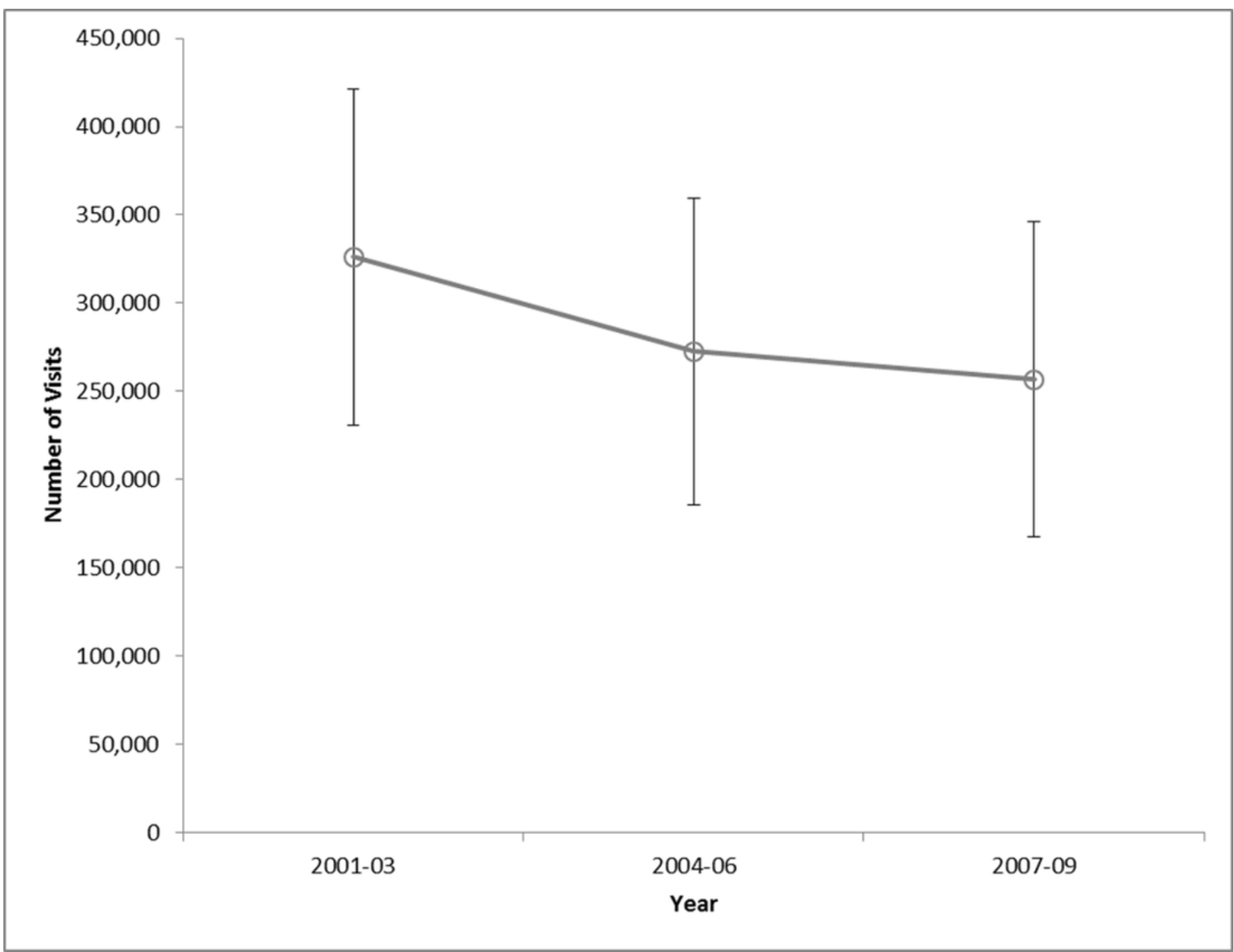

